\title{
Article
}

\section{Elite athletes coping with depression: A qualitative study}

Lebrun, F., Macnamara, Aine, Collins, David John and Rodgers, S. Available at http://clok.uclan.ac.uk/26597/

Lebrun, F., Macnamara, Aine ORCID: 0000-0002-8110-6784, Collins, David John ORCID: 0000-0002-7601-0454 and Rodgers, S. (2019) Elite athletes coping with depression: A qualitative study. Journal of Clinical Sport Psychology, 13 (3). pp. 351-373. ISSN 1932-9261

It is advisable to refer to the publisher's version if you intend to cite from the work. http://dx.doi.org/10.1123/jcsp.2018-0072

For more information about UCLan's research in this area go to http://www.uclan.ac.uk/researchgroups/ and search for <name of research Group $>$.

For information about Research generally at UCLan please go to http://www.uclan.ac.uk/research/

All outputs in CLoK are protected by Intellectual Property Rights law, including Copyright law. Copyright, IPR and Moral Rights for the works on this site are retained by the individual authors and/or other copyright owners. Terms and conditions for use of this material are defined in the policies page.

\section{CLoK}

Central Lancashire online Knowledge www.clok.uclan.ac.uk

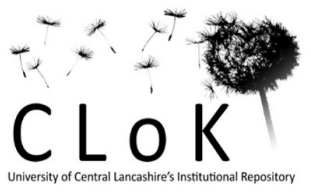


Elite Athletes Coping with Depression: a Qualitative Study

9

${ }^{1}$ Institute of Coaching and Performance, School of Sport and Wellbeing, University of Central

${ }^{2}$ Grey Matters Performance Ltd.

Running head: Elite Athletes Coping with Depression

*Correspondence:

20

Florence Lebrun

E-mail: flebrun@uclan.ac.uk 
Little is known about the coping strategies used by elite athletes suffering from mental health issues. Therefore, this study examined coping strategies implemented by elite athletes' facing clinical depression. Semi-structured interviews were conducted with four elite athletes and analysed using Interpretative Phenomenological Analysis (IPA). Results present a broad picture of how elite athletes tried to cope with depression using a range of coping strategies. Among the different strategies highlighted, talking, seeking professional help and social support were particularly emphasized by the participants. Surprisingly, however, only one participant reported transferring the skills and strategies learned on her way to the top to many other aspects of her everyday life such as coping with her depression. Findings, therefore, suggest that athletes should be encouraged to transfer and make the most of the skills learned throughout their sport career to deal with their daily life. Future research perspectives and implications are discussed. 


\section{Elite Athletes Coping with Depression: a Qualitative Study}

Significant sport literature has focused on the psychological factors required by elite athletes to convert their potential into world-class performance (Collins, MacNamara, \& McCarthy, 2016; MacNamara, Button, \& Collins, 2010; MacNamara \& Collins, 2015; Orlick \& Partington, 1988) as well as on the coping strategies used to deal with sport (e.g., injury, performance issues, competitive and organisational stressors) and non-sport-related (e.g., personal life events, psychosocial stressors) stressors (Kristiansen \& Roberts, 2010; Nicholls \& Polman, 2007; Rice et al., 2016). However, less attention has been paid to the coping strategies employed by elite athletes to deal with mental health issues (MHIs) such as depression. This lack of emphasis is somewhat surprising given that MHIs in elite athletes have attracted considerable attention in recent years (Gouttebarge, Backx, Aoki, \& Kerkhoffs, 2015; Reardon \& Factor, 2010; Rice et al., 2016; Schaal et al., 2011) and that depression, in particular, is a common societal concern that affects both the general and sporting population (Doherty, Hannigan, \& Campbell, 2016; Lebrun, MacNamara, Rodgers, \& Collins, 2018; WHO, 2018). Although the prevalence of depression amongst elite athletes remains unclear (Beable, Fulcher, Lee, \& Hamilton, 2017; Reardon \& Factor, 2010; Rice et al., 2016) and is often underestimated (Hammond, Gialloreto, Kubas, \& Davis, 2013), the occurrence of depressive symptoms is currently thought to be comparable to (Beable et al., 2017; Gulliver, Griffiths, Mackinnon, Batterham, \& Stanimirovic, 2015), or greater (Roberts, Faull, \& Tod, 2016) than the general population.

Whilst some MHIs first appear during adolescence and young adulthood (Kessler et al., 2005; Rickwood, Deane, Wilson, \& Ciarrochi, 2005), the prevalence of clinical symptoms related to a mental condition seem to be greatest among young people aged 16 to 34 years of age (Gulliver, Griffiths, \& Christensen, 2012; Gulliver et al., 2015). Interestingly, this timeframe coincides with the period of peak performance in sport (Rice et al., 2016; Sebbens, 
Hassmén, Crisp, \& Wensley, 2016). As such, the existence of depressive disorders in elite sport is, perhaps, unsurprising given this overlap (Gulliver et al., 2012; Kessler \& Bromet, 2013). Elite athletes are confronted with unique physical and psychological stressors inherent in their sporting career that may increase their vulnerability to MHIs (Gulliver et al., 2012; Rice et al., 2016; Wolanin, Gross, \& Hong, 2015). In addition to the risk factors already found in the general population (Reardon \& Factor, 2010), overtraining, injuries, competitive failure, aging, retirement from sport (Reardon \& Factor, 2010), recurrent surgeries, career dissatisfaction, adverse life events, and lower levels of social support (Gouttebarge et al., 2018; Gouttebarge et al., 2017; Rice et al., 2016) are just some of the factors found in elite sport that may lead to the development of MHIs. In a recent paper, Gouttebarge et al. (2018) estimated that the incidence of symptoms of common mental disorders (CMD) within a cohort of professional rugby players was $11 \%$ for distress, $28 \%$ for anxiety/depression, $12 \%$ for sleep disturbance, $11 \%$ for eating disorders, $22 \%$ for adverse alcohol use while $13 \%$ of their sample presented simultaneous symptoms of CMD. These findings support previous research with professional athletes from other sports (Gouttebarge et al., 2015; Gouttebarge et al., 2017; Gouttebarge, Tol, \& Kerkhoffs, 2016).

Despite growing interest (Doherty et al., 2016; Gouttebarge et al., 2015; Gouttebarge et al., 2018; Gulliver et al., 2015; Hill, MacNamara, Collins, \& Rodgers, 2016), there is still a dearth of information concerning the prevalence and manifestation of clinical depression in elite sport. On one hand, this can be explained by the gap between the true prevalence of MHIs in sport and the MHIs that are actually treated (Henderson, Evans-Lacko, \& Thornicroft, 2013) or self-reported (Gorczynski, Coyle, \& Gibson, 2017). On the other, a lack of consensus in regard to the criteria of MHIs and the lack of psychometric measures specifically adapted to elite athletes could be another explanation for the lack of quality research on MHIs in elite athletes (Lebrun \& Collins, 2017). In the absence of specific data, 
the precise incidence of clinically diagnosed MHIs, such as depression, faced by elite athletes cannot be accurately estimated. However, despite the lack of consensus about the prevalence of depression in elite sport (Reardon \& Factor, 2010), encouraging athletes to develop and deploy a range of coping strategies seem indispensable for both well-being and performance outcomes. While this is important for elite performers in general it may be even more pertinent for athletes suffering from MHIs in order for them to better deal with their condition.

Coping, defined by Lazarus and Folkman (1984) as "constantly changing cognitive and behavioural efforts to manage specific external and/or internal demands that are appraised as taxing or exceeding the resources of the person" (p. 141), is a key concept regarding an individual's adaptation and health (Lazarus, 1993). In other words, coping is mostly a self-regulatory mechanism, consisting of cognitions and behaviours, aimed at helping individuals deal with a variety of stressors (Nicholls, Taylor, Carroll, \& Perry, 2016). Following Lazarus and Folkman (1984)'s definition, various forms of classifications and labels have been developed in the literature (Nicholls \& Polman, 2007; Richards, 2011). The coping categories most widely used are problem-, emotion-, appraisal-focused, and avoidance coping. These categories classify coping strategies based on the intention and function of the coping efforts (Lazarus \& Folkman, 1984). Problem-focused coping, for example, purposely addresses and alters the stressful situation (e.g., seeking information, planning, setting goals) while emotion-focused strategies address the internal and emotional responses caused by the situation/stressor (e.g., seeking emotional support, relaxation, meditation; Lazarus, 1993; Nicholls \& Polman, 2007; Richards, 2011). Appraisal coping includes cognitive strategies, such as restructuring, which aim to re-evaluate the situation and modify the initial thinking processes and thoughts responsible for perceiving a situation as a challenge or a threat (Nicholls \& Polman, 2007; Richards, 2011). Avoidance coping refers to cognitive (e.g., 
cognitive distancing, blocking) and behavioural (e.g., removing self from the situation) strategies that allow individuals to avoid, escape, or deny a situation (Nicholls \& Polman, 2007; Richards, 2011). Although the sport literature tends to consider problem-focused strategies as the most effective approach to dealing with stressors (Lazarus, 1993; Nicholls \& Polman, 2007), the effectiveness of coping strategies is dependent on both the context and the individual, as well as on the outcomes being sought (Lazarus, 1993).

As previously stated, research on coping strategies used by elite athletes suffering from depression is still in its infancy. However, Doherty et al. (2016) have found that elite male athletes with depression adopted both non-adaptive (e.g., isolating themselves from of social support, using alcohol, lack of understanding of depression from others, overtraining) and adaptive (e.g., commitment to recovery, accepting and expressing real self in therapy and being supported by significant others) coping processes. Perhaps related to the use of these coping strategies, Beable et al. (2017) highlighted the relatively low use of antidepressant medication in athletes compared to the general population. Within the general population, where the use of coping strategies has been studied more extensively, help-seeking behaviours such as talking to others and social support (Alexander, Haugland, Ashenden, Knight, \& Brown, 2009; Biringer, Davidson, Sundfør, Lier, \& Borg, 2016; Cornford, Hill, \& Reilly, 2007; Fogarty et al., 2015), physical activity (Biringer et al., 2016; Daley, 2008; Fogarty et al., 2015), positive thinking (Alexander et al., 2009; Biringer et al., 2016), meditation (Fogarty et al., 2015), engaging in pleasant or neutral activities (Alexander et al., 2009; Fogarty et al., 2015; Liu \& Thompson, 2017), and more conventional approaches such as medical treatments (Cornford et al., 2007) or psychotherapies (e.g., CBT; Alexander et al., 2009) have been reported as strategies used to cope with depression. Although various coping strategies differentially impact one's level of depression, the processes by which they might influence one's symptoms are not always well understood (e.g., physical activity; 
Daley, 2008). Coping strategies are believed to help people suffering from MHIs by alleviating the inner turmoil, helping them to forget their problems (e.g., active and resourceful everyday life), and gain some inner peace (Biringer et al., 2016). Alexander et al. (2009), for example, suggested that strategies such as positive thinking, talking to someone, or even spirituality could counteract hopelessness, isolation and despair in people with suicidal thoughts while pleasant activities (e.g., physical exercise, listening to music, working, experiencing nature, etc.) can help an individual to focus on something else or serve as a source of distraction from their worries and depressing thoughts (Alexander et al., 2009; Biringer et al., 2016; Daley, 2008). As such, it seems important to consider the role of coping strategies in dealing with MHIs, especially given that people can adapt their use according to their needs (e.g., mood, symptoms or problem severity; Fogarty et al., 2015).

From a performance perspective, a range of psychological skills have been shown to be facilitative of both development to, and performance at, an elite level (Bartulovic, Young, \& Baker, 2017; Collins et al., 2016; Gould, Dieffenbach, \& Moffett, 2002; MacNamara et al., 2010; MacNamara \& Collins, 2015; Orlick \& Partington, 1988). Indeed, there is a considerable evidence base attesting to the development and deployment of psychological skills as a means of coping with the stressors of the performance trajectory and environment (Kristiansen \& Roberts, 2010; Nicholls \& Polman, 2007; Savage, Collins, \& Cruickshank, 2016; Toering, Elferink-Gemser, Jordet, \& Visscher, 2009). Given the (presumed) prevalence of MHIs in sport, and depression in particular, this study sought to explore the coping strategies employed by athletes to deal with depression in order to support the development of proactive and preventative interventions that may build on the elite athletes' established psychological skillset. Therefore, the purpose of this study was to identify and examine the coping strategies implemented by elite athletes suffering from depression in order to increase our understanding of elite athletes' subjective experience of MHI(s). 


\section{Participants}

Four successful elite athletes ( 1 female, 3 males (Mage $=33$ years, $\mathrm{SD}=4.82$ ) who

"not only compete at the highest level, but have experienced some success at that standard

(e.g., winning an event or a medal)" (Swann, Moran, \& Piggott, 2015, p. 11) were

purposefully sampled. In order to meet our inclusion criteria, participants had to be over 18 ,

to have/had experienced a formally diagnosed MHI(s) (e.g., depression; cf. World Health

Organisation, 2016) during or immediately after ending their athletic career, and to have their condition safely under control or be free of any ongoing MHI(s) at the time of the interview.

Participants were invited to participate via e-mail through a network of professional contacts.

Two individual sport athletes and two team sport athletes agreed to take part in the present study. At the time of the interviews, two participants were still competing at an elite level while two had just retired (see Figures 1-4).

179

\section{Procedure}

Ethical approval was granted from the authors' Institutional Ethics Committee and informed consent was obtained from each participant prior to interview. Since the main aim of the present study was to generate an in-depth understanding of the coping strategies used by each participant, interpretative phenomenological analysis (IPA) was chosen to examine each narrative in detail. Using semi-structured interviews, data were collected in two phases. In the first phase, a graphic time line reporting key events related to their mental health problem(s) and career was drawn by each participant (see Figures 1-4). This aided recall method not only offered a picture of participants' mental health and performance fluctuations around their episode of clinical depression but also offered a means to improve the precision of retrospective recalls by using landmarks events (Drasch \& Matthes, 2013). Building on this first stage, the second stage of the interview employed an interview guide specifically 
developed for the purpose of this study to ensure that each participant was asked the same set of questions about their experience of depression (e.g., what kind of issues did you suffer from? How did it affect you? What was your reaction after getting the diagnosis? What did you do? Were any efforts made to overcome those issues? What key characteristics/strategies would you say are necessary, as an elite performer, to deal with mental health issues?).

Probes and prompts were used for the clarification and elaboration of relevant points raised by each participant (Drasch \& Matthes, 2013; Jones, Brown, \& Holloway, 2013). Questions avoided the use of jargon, were open-ended, and were framed as simply as possible using examples for clarification when necessary. Although the interview guide and graphic timeline were used to guide the discussion, participants were given the opportunity to freely share their subjective experience while at the same time ensuring a certain uniformity between interviews (Jones et al., 2013). The one-on-one interviews lasted about 90 minutes and were conducted face-to-face by the first author. All were audio-recorded and transcribed verbatim.

Pilot study. Pilot interviews were carried out with two male athletes (mean age $=33$, $\sigma=5.657$ ) meeting the aforementioned inclusion criteria. After the interview, the participants gave feedback on the overall content of the interview. Changes regarding the order of two questions was the most noticeable modification made to improve the original interview script.

\section{Data Analysis}

Data were analysed using Smith and Osborn (2007) and Biggerstaff and Thompson (2008)'s guidelines to IPA. All transcripts were read multiple times along with the original recordings allowing the first author to become as familiar as possible with their content. During this familiarising phase, the first author's thoughts, observations, and other comments were recorded and annotated. Meaningful units reflecting participants' quotes were then highlighted, commented and followed by the coding of initial themes (Nicholls, Holt, \& Polman, 2005; Smith \& Osborn, 2007). The revision tools on Word were used in order to 
easily share thoughts, observations, quotes, comments and initial themes between the researchers. Those initial themes and comments allowed us to capture the core of each meaningful unit while also taking into consideration the researchers' own interpretations (Nicholls et al., 2005; Smith \& Osborn, 2007). This process was repeated for each transcript until original meaningful units were all coded into themes. Similar themes were clustered together and given a name representing a higher order theme. An overall structure to the data set of each transcript was subsequently achieved by the realisation of an hierarchical inventory of the themes (Biggerstaff $\&$ Thompson, 2008). Patterns across the transcripts were considered after analysis was completed (Smith, 2011). The divergences and convergences between the transcripts were of particular interest (Smith, 2011; Smith \& Osborn, 2007). Each of the themes is presented in the results section using anonymised quotations which emphasized the similarities and dissimilarities between the interviews as well participants' subjectivity (Smith \& Osborn, 2007). In order to ensure confidentiality and anonymity, participants are referred to by numbers. Furthermore, and for the sake of clarity and ease of comprehension, common coping classifications often reported in the sport psychology literature were used to give an overall description on how participants responded to depression. Although those classifications imply that each strategy can only fit in one theoretical and functional category, we acknowledge that a single strategy could serve different functions depending on the context and on the individual (Gaudreau \& Blondin, 2002; Richards, 2011). As such, we acknowledge that the classification was dependent on the authors' interpretation.

Trustworthiness. Trustworthiness was ensured by the use of peer-debriefing, thick description (Jones et al., 2013), and member-reflection (Smith \& McGannon, 2018). Peerdebriefing was achieved via the research team's feedback and challenges to the first author throughout the study but in particular during the data analysis phase (Jones et al., 2013). For 
example, the second author, an experienced qualitative researcher who had not been involved in the data collection, critically analysed and reviewed the first author's data analysis and interpretation. Authors 1 and 2, then discussed the data analysis enabling them to consider each other's understanding and interpretation of the data. Following these steps, authors 3 and 4 played the role of critical friends and reviewed the codes and themes generated during the initial data analysis (Jones et al., 2013). Member reflection provided the participants with an opportunity to give feedback on the themes generated from their own transcript as well as to reflect and comment on the overall findings. Participants were provided with an overall summary of the data encompassing a table summing up the different themes generated from the entire set of data as well as a more specific summary of the results generated from their own data. This summary was accompanied with an explanation of each theme and sub-theme as a way to highlight the logic behind the analysis. This dynamic process allowed participants and researchers to engage in order to confront their understanding of those data (Smith \& McGannon, 2018). While all participants were contacted for member reflection, only one participant took the opportunity to engage in this process and offer reflections on the data set. Following this, results were discussed, triangulated, and reworked by the whole research team until a consensus was found. Finally, the richness of the data was preserved by presenting the findings using thick and direct quotations in order for the readers to hear the participants' own voice as well as grasp the logic behind the analysis (Jones et al., 2013).

\section{Results}

The main objective of the present study was to identify and examine the coping strategies used by elite athletes to deal with clinical depression. Participants reported a variety of comorbidities such as attention deficit/hyperactivity disorder (ADHD; Participant 1), anxiety issues (Participants 1, 3 and 4) and obsessive and compulsive disorder (OCD; Participant 4) in addition to the formal diagnosis of depression made by a general practitioner (GP; $n=2)$ or a 
psychiatrist $(\mathrm{n}=2)$. However, reflecting the aims of the study and the diagnosis of clinical depression that was common across participants, the results will focus solely on the coping strategies implemented to address depression.

\section{How Do Elite Athletes Cope with Depression?}

Problem-focused strategies. As a means of coping with depression, all participants described how they attempted to change the situation they were in. For example, all the participants described help-seeking behaviours such as seeking out tangible and informational support from a variety of formal sources (e.g., GP, psychiatrist, counsellor, social worker; Rickwood \& Thomas, 2012). Participant 1 exemplified this through his description of the journey he went through in order to get help:

I tried to get help. I accessed the EIS [English Institute of Sport] and BUPA [Health Insurance Company] healthcare (...), so I managed to reach out to a doctor. They then diagnosed me and put me on some medication. They also put me onto sessions with the Priory [treatment centre].

Participant 2 also described how he was encouraged to seek help by his family and, specifically, by his father. Whilst social support associated with family is often considered as emotional coping in some cases, as illustrated by Participant 2, it can lead to more tangible and informational support:

My dad mentioned it. He said, when I opened up he just said, 'I think you're suffering from depression (...) then we decided to go and see my GP, put me on some antidepressant medication and then I got talking to a counsellor.

Participant 3 described a very similar journey describing how her GP, who had made the initial diagnosis, encouraged her to take some time off work and see a counsellor: I went into the doctor's appointment and I just couldn't speak. I just cried for about half an hour and overran several other people's appointments. And then 
he's like, 'you can't work if you're like this. It is better if we sign you off (...). I did everything I could think of. I had counselling (...).

293

Illustrating the range of sources of support that were availed of, Participant 4 described his help-seeking journey as follows:

I went to my GP who referred me to [Hospital's Name] which is a mental hospital in [City's Name] which is my hometown (...). So, I originally saw a social worker while we were waiting and then saw both a psychologist and a psychiatrist and it was the psychiatrist who diagnosed the OCD.

Seeking treatment and appropriate social support are critical resources to deal with MHIs such as depression (Talebi, Matheson, \& Anisman, 2016). However, and as with the general population (Cornford et al., 2007; Rickwood \& Thomas, 2012), seeking professional help and conventional medical treatment was only one of the coping strategies employed by these elite athletes.

Emotion-focused strategies. Participants employed a variety of strategies in order to address the emotional responses caused by their depression. These strategies ranged from emotional eating, stress decrease strategies (e.g., relaxation, meditation, acupuncture, etc.), and various ways to vent unpleasant emotions such as seeking emotional support from a variety of sources or becoming a spokesperson and sharing their experience with others (e.g., talks, interviews). Participant 1 , for example, mentioned both the informational and emotional help he received from his counsellor and how he was able to combine this with other coping strategies such as meditation: "The Priory helped me with like their psychological input and stuff. But then I started using things like Headspace [meditation app].” In a similar manner to Participant 1, Participant 2 sought support from a professional counsellor and became a fervent advocate of the benefits of talking therapies. Talking was also emphasized by Participant 2 as the most important and effective step on his path to 
recovery (e.g., "And then I got talking to a counsellor and talking and talking and talking just saved my life."). Aware of both the stigma associated with MHIs and of the importance of talking, Participant 2 decided to share his story publicly with others and used it "as like a therapy because it is good to speak about what I went through and I feel it was really, really useful." Like Participant 2, Participant 3 and 4 shared their experiences with others via different channels. Furthermore, Participant 3 also mentioned a range of different strategies she employed to address her emotional state. In addition to counselling and talking (e.g., to her coach and sport psychologist), she also tried hypnotherapy, acupuncture, and meditation. According to her:

I did everything I could think of. I had counselling, hypnotherapy, meditation. I spoke, speaking to my coach maybe helped, speaking to Name, sport psychologist helped (...). I started doing meditation (...). I'm trying acupuncture at the moment. I'm always trying to try different things to see what helps (...). Well meditation does help and I think I'm always a busy person and my mind is always busy. So, I think it's good for me anyway to calm the mind down (...).

In addition to working with charities, Participant 4 also used other strategies such as engaging in emotional eating to feel better (e.g.: "I eat a lot of food when I'm feeling low makes me feel better. So chocolate, ice cream, crisps. It makes me feel happier.").

Moreover, all participants emphasised the importance of the emotional support provided by their entourage (e.g., friends and family; Rickwood \& Thomas, 2012).

Participant 1 , for example, explained how his family and friends were "there for" him when he was suffering from depression:

My family is lovely so like in no way when they talk, people talk about bad parenting, like my family's the epitomy of a great family. And we were talking about generally 
people outside of sport, actually quite good for mental health (...) like friends and everything like that are wonderful.

Participant 2 also described how talking in general, and in particular to his family and friends,

343 became a big component of his life and a means of coping with depression symptoms. He explained how: ... just chatting with your mates. It's, even if you're not talking about your problems, even if you're talking about utter rubbish you're still breaking things down and you're getting things off your chest .(...) I don't keep anything bottled up any more. If anything's getting on top of me I'll speak to me wife, I'll speak to me parents. People think it can't be that easy but talking is, honestly, it's saved my life.

The importance of social support, and even just "having someone to talk to", was also reported by Participant 3:

The most important thing is support from other people and being able to talk to someone that understands it yeah. (...) I think talking to other people is more important than any other tool, I suppose. Just being able to get things off your chest and say things, even if they seem irrational.

Similarly, Participant 4 received a lot of emotional support from his friends, family and, teammates. Perhaps surprisingly given the significance places on peers and teammates in sport (Bianco, 2001), Participant 4 was the only one who mentioned teammates as a source of support:

So I talked to my fiancée about it, I talked to just friends and even sometimes I'm feeling really down and say to my friend 'I'm feeling really down at the minute' and then talk for a couple of minutes and all of a sudden you're feeling better just for saying it. Like doesn't necessarily mean like it's like magic or anything like that but it yeah I feel better just for you know having people to talk to, having told people makes 
a massive difference (...) if I have a bad game I know my teammates will be keeping an eye on me making sure everything's OK but that's just their way of caring and showing support.

Although the importance of having a good social support network was emphasized by all the participants, they were also aware of the potential negative impact others could have on their depression. Participant 1 , for example, explained that when he announced his retirement “everyone kept asking me, 'so what are you gonna do?' And I'm like, 'I ain't got a clue", and described how these remarks weren't helpful at that time. Negative forms of social support was also reported by Participant 3 in the form of unsolicited or unwanted advice "The only annoying thing is people trying to give me advice and...that's just another athlete's opinion and what do they know compared to what the consultant knows. So that, the unwanted advice frustrates me". Despite good intentions, undesired support can be as unhelpful or harmful as inadequate or a lack of support as one's needs are not met (Bianco, 2001).

Appraisal-focused strategies. Cognitive restructuring and/or reappraisal strategies (e.g., positive thinking, acceptance, alternative thoughts, etc.) were mentioned by three out of the four participants. Participant 1 , for example, tried to reappraise his situation by using a mix of positive thinking and alternative thoughts allowing him to put his situation and thoughts into perspective:

It's like an existential crisis, you kind of reframe and look at things. And you kind of understand happiness is a different equation to what's been shoved down your face (...) whereas before I would be very impulsive, so you said something, I'd go, 'oh that must be right because I cannot be wrong. Whereas now I'm just like, 'no it doesn't necessarily mean that at all. There's no absolute.' (...) Instead of thinking, 'oh okay, life is', there's so many other things like it doesn't matter. It just doesn't matter. In the grand scale of things what's going on it really doesn't matter. 
to alter her thought patterns using positive thinking, acceptance, and taking the time to look

392

393 for alternative thoughts:

Just trying to change the thought processes and all the suggestions that I get from the counsellor or from my coach or Name [sport psychologist] (...). And maybe meditation helps with that as well because as soon as you realise you're having unhelpful thoughts, just try and forget it and think of something else. Yeah try and replace it with a positive thought or just move on and just don't think about that anymore (...). I guess I would always be frustrated that something had happened and wishing I could change it. But then now accepting you can't change what has happened in the past. What can you do now and what can you do right now, this minute (...). I guess if something genuinely bad happens it puts other things into perspective. So, I do make more efforts to sort of step back and have time to think before reacting to things.

Participant 4 described how he employed a range of cognitive strategies including acceptance of his mental state and the role played by his OCD, re-evaluating his thoughts in a more rational way, as well as using alternative thoughts in order to cope with his depressive thoughts:

I've accepted that I do have an illness and times I feel very, very low, so it can be because it can be torture for yourself to think you know if this has happened, if this has happened, if I was better at this, if I was better at or that, if I was better at [sport] there then I'd be instantly happier. You can certainly think God that's torture, whereas now I'm thinking 'OK I wanted to be a better [sport] player I want to be better at all these things. But it doesn't necessarily mean I'm going to be genuinely happier'. And that's the single biggest thing which lead me to feeling better. 
Although three of the participants used a variety of cognitive restructuring strategies, Participant 3 was the only one who explicitly described how she was able to transfer the skills she learned from her sport psychologist (e.g., goal setting, cognitive strategies) for performance enhancing effects to handle her anxiety and depressive thoughts: I think a lot of the skills from sport psychology are useful in other situations as well. Just about if you can't control something then don't waste your energy worrying about it. And what are the things that you can, what can you change and focus on that instead (...). I think it is good to learn the skills of sport psychology, of focusing on the helpful things and try and not to think about unhelpful things and things you can't change (...). Everything to do with sport, the harder you work for something then you improve and you move toward your goals.

Avoidance strategies: Participants described various avoidance strategies such as physically removing self from a stressful situation (e.g., leaving the problematic environment) and engaging in new activities (e.g., physical activity, new hobbies, working with charities) as ways to deal with depression. Illustrating this, Participant 1 purposefully started to search for new interests in an effort to distance himself from the sport environment responsible, according to him, for his depression. He reported: I started finding things which interested me because up until then I didn't have anything because it was monopolised by [sport]. I just started to do things more what I wanted to do (...). Going back home, I lived with my parents for about three months whilst I got better.

In a similar fashion, Participant 2 started new activities outside of his sport and became involved with charities: 
Doing stuff for charity and doing stuff for other people makes me feel good about myself (...). I also got into physical activity as well, although I couldn't run or do anything much but I got into boxing. And that was another antidepressant that I used.

Participant 4 also described the positive impact exercising had on his mood:

Exercising in general can lift the mood so sometimes feeling very low and don't want to train don't want to go and then finish afterwards and just feel pretty good (...). Sometimes I'm feeling low and then I go, we have like, a training session makes me better afterwards but sometimes you feel bad after training, sometimes, you feel good going for a session feel bad afterwards so yeah (...).

However, unlike Participant 2's new physical activity, Participants 3 and 4 - for whom the perceived triggers behind their depression were not related to their sport participation - also mentioned training and competing as helpful strategies. Participant 3, for example, explained that:

Training is like a release, and in every other situation, training's always made me feel better and feel back to normal again (...). I did start training as soon as I could. And it did, it did make me feel better (...). All my ambitions are then in sport. So that's what drives me and I need to ..., it just makes me happy to achieve something and work hard in sport. And then that's where I get satisfaction from.

While distracting strategies had a positive impact on participants' emotional state, other avoidance strategies such as postponing help seeking or denying a problem until it is not possible to do otherwise could be considered as detrimental. (Un)consciously postponing help seeking could be related to some cognitive distance in the form of denial. Even though the participants did not explicitly report postponing help seeking, there appeared to be a delay between the manifestation of symptoms and the implementation of help seeking behaviours. Three out of four of the participants had suicidal thoughts or plans to commit suicide before 
they sought help. Participant 1 explained how, even after seeing a GP and receiving medication, he waited for his condition to worsen before seeking help from a counsellor: So from diagnosis in 2014, I did nothing apart from taking an antidepressant which was prescribed to me. 2015, again no, no...like until I snapped my knee and then I'd become even more suicidal (...). So it would have been actually 2014 , I think, the, the initial GP diagnosis. And then it would have been about 2015, it would have been about June, July I started seeing the woman at the Priory.

Participant 2 mirrored these behaviours and waited to the point where he had suicidal ideation to seek help, and only then as a result of encouragement from his family. As he described: I found myself in [City] in my car, gonna take me own life. I had a box full of pills, strongest drugs you can get (...). Oxynorm, Oxycotin, the strong morphine based drugs. I was gonna take my own life. And for some reason I don't know why I didn't whether it were my kids or my wife or my parents, I couldn't tell you because I was in a total different place (...). I've got a real close family around me and they'd noticed a big difference in my personality and it was them that saved my life really (...). And we spent hours talking and crying and then we decided to go and see my GP.

In a similar fashion, Participant 4 described how it took him years to finally seek help. Indeed, this participant recounted how, even though he suffered from suicidal thoughts since his childhood, he only sought help in adulthood:

I struggled with mental illness since a young age. I first remember having thoughts of self-harm around 8 or 9 and then I eventually went to first see a Doctor about it in January of 2014 (...). I first went to the Doctor at 26. I would've, yes so diagnosed around that time $26 / 27(\ldots)$.

Upon reflection, Participant 4 realised he should have sought help sooner but felt, at the time, that he didn't have the information, or ability, required to make such a decision. 
Around that age if someone had said to me, if there was a load of mental health campaigns, if there was people I looked up to in [sport] and in other sports talking about their mental health and they've got it then I'd have been like 'Oh OK well this isn't something that I should be scared of this isn't something that I should be ashamed of' and would've gone to the Doctor (...). I knew it wasn't right but I was ashamed of it because it was perceived as weakness at the time. Whereas if someone who I'd looked up to had it I'd have been like 'Oh well if that person has it then you know it's OK'.

\section{Discussion}

The purpose of this study was to identify and examine the coping strategies implemented by elite athletes who had been diagnosed with depression within the larger context of their subjective experience of $\mathrm{MHI}(\mathrm{s})$. On first review, our findings offer little new data but rather confirm studies previously conducted in the general population that people with depression tend to use a variety of strategies to manage their MHIs (Alexander et al., 2009; Biringer et al., 2016; Cornford et al., 2007; Fogarty et al., 2015; Liu \& Thompson, 2017). On a deeper examination, however, the present findings consider the ways participants responded to their experience of MHIs and highlight the wide and mixed range of problem(e.g., help-seeking behaviours), emotion- (e.g., emotional eating, stress decrease strategies, venting unpleasant emotions), appraisal- (e.g., cognitive restructuring, reappraisal strategies), and avoidance (e.g., removing self from a stressful situation, physical activity, new hobbies, postponing seeking from help) strategies used, alone or in combination, by athletes to cope with depression.

As with the general population, athletes used conventional medical treatment in combination with a broad range of other strategies to cope with their depression (Cornford et al., 2007; Rickwood \& Thomas, 2012). Participants particularly emphasised the importance 
of talking and reaching for professional help, supporting previous research stressing the key role talking to others about one's problems (e.g., to a trusty professional, family member or friend) and having a safe place to express ones' emotions (Alexander et al., 2009; Doherty et al., 2016; Fogarty et al., 2015) can have in the recovery process (Biringer et al., 2016; Doherty et al., 2016). Appropriate social support is certainly essential as it can, when perceived as matching one's needs, facilitate the implementation of coping strategies, help individuals to acknowledge a problem, and encourage them to seek professional help (Bianco \& Eklund, 2001; Cornford et al., 2007; Doherty et al., 2016; Gulliver et al., 2012; Talebi et al., 2016). An effective social network of family, peers, and companionship is important for people with suicidal ideation due to the role of connectedness in recovery (Alexander et al., 2009). Therefore, and given that social support can take on different forms (e.g., emotional, tangible, and informational) and can be offered by various sources (e.g., family, friends, teammates or health professionals), it seems crucial that people suffering from MHIs are made aware of the social support and "resources" that are at their disposal as well as being given the ability and support to use these resources appropriately (Bianco \& Eklund, 2001; Rickwood \& Thomas, 2012). However, despite the importance attributed to social support, few studies have investigated the nature of the social support athletes suffering from MHIs receive from within their sport environment. This stands in contrast to the importance of seeking and using social support as a performance-focused aid (MacNamara \& Collins, 2015). Future research on the social support athletes suffering from MHIs actually receive, perceive to receive, and/or need (e.g., type of support, provider, etc.) is, therefore, warranted. Supporting previous research conducted in the general population (Biringer et al., 2016; Cornford et al., 2007; Fogarty et al., 2015), our findings also highlighted athletes' use of diverse cognitive restructuring and/or reappraisal strategies (e.g., positive thinking, acceptance, alternative thoughts), stress-decreasing strategies (e.g. relaxation, meditation), 
and distracting activities in managing MHIs. While cognitive strategies were used by the participants to reappraise the meaning of the emotion-eliciting situation and regulate the emotions attached to it (Lazarus, 1993; Liu \& Thompson, 2017), distracting strategies were used to "purposeful turning one's attention away from one's symptoms of depression and its possible causes and consequences to pleasant or neutral activities" (Nolen-Hoeksema, 1991, p. 570; cited in Liu and Thompson, 2017). Some of the activities reported by the participants (e.g., being involved in charity, physical activity, etc.) are consistent with findings highlighting the usefulness of changing one's emotional and cognitive states by engaging in pleasant or neutral distracting activities (Biringer et al., 2016; Liu \& Thompson, 2017).

Furthermore, physical activity could be seen as a way to distract individuals from anxious and/or depressive thoughts (Daley, 2008). It was, however, interesting to note that physical activity, training, and competing only were used by the participants for whom depression was not considered as related to their sport participation. When depression is a consequence of sport participation, a break away from the sport environment could help athletes associating their depression to their sport participation or environment to better deal with their distress (Doherty et al., 2016). As such, it is important that both the individual and the context in which the problem occurs (Lazarus, 1993) are carefully considered. In this regard it has been suggested that participation in elite sport could either help athletes cope with MHIs or be a trigger for MHIs (Reardon \& Factor, 2010).

Understanding the context and complexities of elite sport is clearly an important step. For example, three participants postponed seeking professional help until they were confronted with suicidal ideation. While this delay in seeking help might be partly explained by the stigma and embarrassment surrounding mental health in sport (Addis \& Mahalik, 2003; Gulliver et al., 2012), the difficulty to discriminate between normal feelings and MHI symptoms might be another explanation (Cornford et al., 2007). Critically however, the 
reluctance to seek professional help is one of the biggest challenges in the treatment and prevention of MHIs, especially for men (Addis \& Mahalik, 2003; Gulliver et al., 2012; Rickwood \& Thomas, 2012; Talebi et al., 2016). As a result, by the time individuals finally seek help, their condition has often worsened from a subclinical to a clinical level of severity and impairment (Schinke, Stambulova, Si, \& Moore, 2017). In order to improve the early detection of MHIs, and prevent subclinical issues evolving into clinical disorders (Schinke et al., 2017), an important step in a performance context would be to increase athletes', and their entourages', awareness of MHIs and their ability to seek for help and support when necessary (e.g., when, who, and where to go; Lauber, Nordt, Falcato, \& Rössler, 2003). It was noteworthy that participants in the present study also came to this conclusion and, like Gulliver et al. (2012), believed that by sharing their stories and increasing MHIs visibility in sport environments they could encourage others currently in the same situation to reach for help.

Perhaps the most interesting finding was the overlap between the categories of coping strategies highlighted in the present study and those found in previous research on how sport performers cope with sport and organisational stressors (Kristiansen \& Roberts, 2010; Nicholls \& Polman, 2007). Although only Participant 3 explicitly reported employing the psychological skills learned in sport as performance enhancing strategies to deal with her MHI (e.g., focus and cognitive strategies), both the present data and previous studies (Gould \& Carson, 2008; Kendellen \& Camiré, 2019) suggest the possibility of a skills-based transfer from sport to daily life. There is a significant body of literature supporting the importance of psychological skills as precursors of sporting excellence. As such, performers must develop and use a range of skills and strategies to self-monitor their progress, as sources of errors and needs (e.g. gathering information; Bartulovic et al., 2017), to cope effectively with the 
inevitable 'ups and downs' encountered as they progress in sport (Gould et al., 2002;

MacNamara et al., 2010).

\section{Clinical Implications}

Of course, the present findings do not offer a selective list of strategies that athletes should systematically apply when confronted with MHIs. Instead, given that athletes already have developed a range of coping strategies through their engagement in elite sport, the present results suggest that athletes could be supported to use the knowledge and skills learned to cope with sport challenges in order to better handle other kind of challenges such as dealing with MHIs. A logical focus of psychological support in sport would, therefore, be on the development of a broad range of psychological skills, supporting both athletes' ability to monitor their own well-being and their ability to deploy those skills to deal with challenges from both within (e.g., injury, deselection) and outside (e.g., MHIs) of their sporting lives (Collins, MacNamara \& Cruickshank, 2018). Although such interventions may not prevent the development of MHIs, nor explicitly and solely enable athletes to self-address such issues, increased knowledge about MHIs and mental skills may promote skills transfer by increasing athletes' understanding on how skills learned in a sporting context can be transformed and applied to respond to the demands encountered in other contexts (e.g., opportunities, needs, or benefits of life skills transfer; Kendellen \& Camiré, 2019). In addition, this type of intervention may also provide athletes with sufficient awareness and tools to monitor, early detect, and fight against developing MHIs. However, in order to be as efficient as possible, this type of intervention should be taught in a consumable and informed format (e.g., agerelated, sport-related, role models) taking into account, for example, the help-seeking behaviours and barriers specific to the groups targeted by those interventions (Gulliver et al., 2012). Furthermore, and in addition to existing psychological skills developed by athletes for sport (e.g. quality practice, focus and distraction control, planning, imagery, goal setting, etc.; 

also be learned and developed by elite athletes in regards to maintaining, protecting or dealing with their mental health. The implementation of longitudinal investigations looking to the effectiveness of such interventions is a clear next step.

\section{Limitations and future recommendations}

The present study is not without limitations. While the four participants in this study reported being formally diagnosed with depression and comorbidities (e.g., anxiety, ADHD and OCD), no third party information was sought. Furthermore, despite the use of an aided recall method (Drasch \& Matthes, 2013), some memory decay may impact the results due to the recall of a difficult period of time for the participants. Social desirability is another element worth discussing that may have impacted the results as participants may have been more willing to participate in the present study as a result of their own interest and commitment to increase the public's awareness regarding MHIs in sport. As the effectiveness of the coping strategies implemented was not assessed 'per se', it is worth considering that participants reported "coping strategies" as only those actions they had in mind at the time of the interview or the ones they believed that had a positive impact on their condition. As such, it is important to consider the subjectivity of a person and the whole context surrounding one's journey to recovery (Cornford et al., 2007). Given that, the effectiveness of a coping strategy (e.g., adaptive or non-adaptive) depends on the individual, on the context and on the desired outcomes (Lazarus, 1993), and recognising the retrospective nature of this investigation, a number of coping strategies could have been omitted. Future research may, therefore, be warranted in order to examine the (perceived) effectiveness of the strategies implemented by elite athletes to cope with MHIs. Such future research seem essential in order to maximize the benefits of interventions aiming to help individuals suffering from MHIs such as depression. Furthermore, the small sample size, the inter-variability between 
the participants (e.g., individual versus team sport, males versus female), as well as the uniqueness of the targeted cohort, do not enable the findings to be fully generalised. Nevertheless, in regard to the small sample size, Smith and Osborn (2007) suggested that a small sample of three participants is enough to realise an in-depth and detailed analysis of each participant's data set while big samples may weaken the analysis due to the amount of data generated. Moreover, generally speaking, IPA research is conducted on small samples as this phenomenological approach aims to provide rich and detailed descriptive accounts of how people perceive and make sense of their own lived experience (Smith, 2011). In the present paper, a small sample size was, therefore, chosen to achieve a rich phenomenological data set. Although saturation is not an aim in IPA (Saunders et al., 2018), we considered that saturation was met during the data analysis when no new codes occurred in the data. Future research might consider interviewing more athletes to add to the current findings, examining differences that may exist between type of the sport (e.g., individual versus team), gender, and support structure (e.g., presence or not of a sport psychologist in the athlete's entourage).

\section{Conclusion}

The present study gives a broad picture of how four elite athletes coped with clinical depression. The participants particularly stressed the importance of talking, seeking professional help, and social support. The differences between the coping strategies employed by athletes to navigate challenges associated with sport and the coping strategies used to deal with MHIs were most noteworthy. This suggests that encouraging athletes to use and transfer the skills learned from sport to their every-day life could be an efficacious means of dealing with MHIs. Further research on coping strategies, the resources used by elite athletes to deal with MHIs, and the effectiveness of these approaches is warranted in order to design interventions. Finally, the present study highlights some practical implications such as the need to improve athletes' understanding about MHIs in order to decrease the stigma 
662

663

664

665

666

667

668

669

670

671

672

673

674

675

676

677

678

679

680

681

682

683

684

685

associated with that topic and foster help-seeking behaviours as well as regarding the

usefulness their current skillset may have in response to MHIs.

\section{Acknowledgements}

The authors would like to thank the four athletes who took part in the present study for their time and valuable contribution.

\section{References}

Addis, M. E., \& Mahalik, J. R. (2003). Men, masculinity, and the contexts of help seeking. American Psychologist, 58(1), 5-14. doi:10.1037/0003-066X.58.1.5

Alexander, M., Haugland, G., Ashenden, P., Knight, E., \& Brown, I. (2009). Coping with thoughts of suicide: Techniques used by consumers of mental health services. Psychiatric Services, 60(9), 1214-1221. doi:10.1176/ps.2009.60.9.1214

Bartulovic, D., Young, B. W., \& Baker, J. (2017). Self-regulated learning predicts skill group differences in developing athletes. Psychology of Sport and Exercise, 31, 61-69. doi:10.1016/j.psychsport.2017.04.006

Beable, S., Fulcher, M., Lee, A. C., \& Hamilton, B. (2017). SHARPSports Mental Health Awareness Research Project: Prevalence and risk factors of depressive symptoms and life stress in elite athletes. Journal of Science and Medicine in Sport, 20(12), 10471052. doi:10.1016/j.jsams.2017.04.018

Bianco, T. (2001). Social support and recovery from sport injury: Elite skiers share their experiences. Research Quarterly for Exercise and Sport, 72(4), 376-388. doi:10.1080/02701367.2001.10608974

Bianco, T., \& Eklund, R. (2001). Conceptual considerations for social support research in sport and exercise settings: The case of sport injury. Journal of Sport \& Exercise Psychology, 23(2), 85-107. doi:10.1123/jsep.23.2.85 
Biggerstaff, D., \& Thompson, A. R. (2008). Interpretative phenomenological analysis (IPA): A qualitative methodology of choice in healthcare research. Qualitative Research in Psychology, 5(3), 173-183.

Biringer, E., Davidson, L., Sundfør, B., Lier, H. Ø., \& Borg, M. (2016). Coping with mental health issues: Subjective experiences of self-help and helpful contextual factors at the start of mental health treatment. Journal of Mental Health, 25(1), 23-27. doi:10.3109/09638237.2015.1078883

Collins, D., MacNamara, Á., \& McCarthy, N. (2016). Super champions, champions, and almosts: Important differences and commonalities on the rocky road. Frontiers in Psychology, 6(2009), 1-11. doi:10.3389/fpsyg.2015.02009

Cornford, C. S., Hill, A., \& Reilly, J. (2007). How patients with depressive symptoms view their condition: A qualitative study. Family Practice, 24(4), 358-364. doi:10.1093/fampra/cmm032

Daley, A. (2008). Exercise and depression: A review of reviews. Journal of Clinical Psychology in Medical Settings, 15(2), 140-147. doi:10.1007/s10880-008-9105-z

Doherty, S., Hannigan, B., \& Campbell, M. J. (2016). The experience of depression during the careers of elite male athletes. Frontiers in Psychology, 7(1069), 1-11. doi:10.3389/fpsyg.2016.01069

Drasch, K., \& Matthes, B. (2013). Improving retrospective life course data by combining modularized self-reports and event history calendars: Experiences from a large scale survey. Quality and Quantity, 47(2), 817-838. doi:10.1007/s11135-011-9568-0

Fogarty, A. S., Proudfoot, J., Whittle, E. L., Player, M. J., Christensen, H., Hadzi-Pavlovic, D., \& Wilhelm, K. (2015). Men's use of positive strategies for preventing and managing depression: A qualitative investigation. Journal of Affective Disorders, 188, 179-187. doi:10.1016/j.jad.2015.08.070 
Gaudreau, P., \& Blondin, J.-P. (2002). Development of a questionnaire for the assessment of coping strategies employed by athletes in competitive sport settings. Psychology of Sport and Exercise, 3(1), 1-34. doi:10.1016/S1469-0292(01)00017-6

Gorczynski, P. F., Coyle, M., \& Gibson, K. (2017). Depressive symptoms in highperformance athletes and non-athletes: A comparative meta-analysis. British Journal of Sports Medicine, 51(18), 1348-1354. doi:10.1136/bjsports-2016-096455

Gould, D., \& Carson, S. (2008). Life skills development through sport: Current status and future directions. International Review of Sport and Exercise Psychology, 1(1), 58-78. doi:10.1080/17509840701834573

Gould, D., Dieffenbach, K., \& Moffett, A. (2002). Psychological characteristics and their development in Olympic champions. Journal of Applied Sport Psychology, 14(3), 172-204. doi:10.1080/10413200290103482

Gouttebarge, V., Backx, F. J. G., Aoki, H., \& Kerkhoffs, G. M. M. J. (2015). Symptoms of common mental disorders in professional football (soccer) across five European countries. Journal of sports science \& medicine, 14(4), 811-818.

Gouttebarge, V., Hopley, P., Kerkhoffs, G., Verhagen, E., Viljoen, W., Wylleman, P., \& Lambert, M. (2018). A 12-month prospective cohort study of symptoms of common mental disorders among professional rugby players. European Journal of Sport Science, 18(7), 1004-1012. doi:10.1080/17461391.2018.1466914

Gouttebarge, V., Jonkers, R., Moen, M., Verhagen, E., Wylleman, P., \& Kerkhoffs, G. (2017). The prevalence and risk indicators of symptoms of common mental disorders among current and former Dutch elite athletes. Journal of Sports Sciences, 35(21), 2148-2156. doi:10.1080/02640414.2016.1258485

Gouttebarge, V., Tol, J. L., \& Kerkhoffs, G. M. M. J. (2016). Epidemiology of symptoms of common mental disorders among elite Gaelic athletes: A prospective cohort study. 
The Physician and Sportsmedicine, 44(3), 283-289. doi:10.1080/00913847.2016.1185385

Gulliver, A., Griffiths, K. M., \& Christensen, H. (2012). Barriers and facilitators to mental health help-seeking for young elite athletes: A qualitative study. BMC Psychiatry, 12(1), 1-14. doi:10.1186/1471-244x-12-157

Gulliver, A., Griffiths, K. M., Mackinnon, A., Batterham, P. J., \& Stanimirovic, R. (2015). The mental health of Australian elite athletes. Journal of Science and Medicine in Sport, 18(3), 255-261. doi:10.1016/j.jsams.2014.04.006

Hammond, T., Gialloreto, C., Kubas, H., \& Davis, H. I. (2013). The prevalence of failurebased depression among elite athletes. Clinical Journal of Sport Medicine, 23(4), 273277. doi:10.1097/JSM.0b013e318287b870

Henderson, C., Evans-Lacko, S., \& Thornicroft, G. (2013). Mental illness stigma, help seeking, and public health programs. American Journal of Public Health, 103(5), 777780. doi:10.2102/AJPH.2012.301056

Hill, A., MacNamara, Á., Collins, D., \& Rodgers, S. (2016). Examining the role of mental health and clinical issues within talent development. Frontiers in Psychology, 6(2042), 1-11. doi:10.3389/fpsyg.2015.02042

Jones, I., Brown, L., \& Holloway, I. (2013). Qualitative research in sport and physical activity. London: Sage.

Kendellen, K., \& Camiré, M. (2019). Applying in life the skills learned in sport: A grounded theory. Psychology of Sport and Exercise, 40(1), 23-32. doi:10.1016/j.psychsport.2018.09.002

Kessler, R. C., Berglund, P., Demler, O., Jin, R., Merikangas, K. R., \& Walters, E. E. (2005). LIfetime prevalence and age-of-onset distributions of dsm-iv disorders in the national 

comorbidity survey replication. Archives of General Psychiatry, 62(6), 593-602. doi:10.1001/archpsyc.62.6.593

Kessler, R. C., \& Bromet, E. J. (2013). The epidemiology of depression across cultures. Annual Review of Public Health, 34, 119-138. doi:10.1146/annurev-publhealth031912-114409

Kristiansen, E., \& Roberts, G. C. (2010). Young elite athletes and social support: Coping with competitive and organizational stress in "Olympic" competition. Scandinavian Journal of Medicine \& Science in Sports, 20(4), 686-695. doi:10.1111/j.16000838.2009.00950.x

Lauber, C., Nordt, C., Falcato, L., \& Rössler, W. (2003). Do people recognise mental illness? Factors influencing mental health literacy. European Archives of Psychiatry and Clinical Neuroscience, 253(5), 248-251. doi:10.1007/s00406-003-0439-0

Lazarus, R. S. (1993). Coping theory and research: Past, present, and future. Psychosomatic Medicine, 55(3), 234-247.

Lazarus, R. S., \& Folkman, S. (1984). Stress, Appraisal, and Coping. New York: Springer.

Lebrun, F., \& Collins, D. (2017). Is elite sport (really) bad for you? Can we answer the question? Frontiers in Psychology, 8(324), 1-8. doi:10.3389/fpsyg.2017.00324

Lebrun, F., MacNamara, À., Rodgers, S., \& Collins, D. (2018). Learning from elite athletes' experience of depression. Frontiers in Psychology, 9(2062), 1-11. doi:10.3389/fpsyg.2018.02062

Liu, D. Y., \& Thompson, R. J. (2017). Selection and implementation of emotion regulation strategies in major depressive disorder: An integrative review. Clinical Psychology Review, 57, 183-194. doi:10.1016/j.cpr.2017.07.004 
MacNamara, Á., Button, A., \& Collins, D. (2010). The role of psychological characteristics in facilitating the pathway to elite performance. Part 1: Identifying mental skills and behaviours. The Sport Psychologist, 24(1), 52-73.

MacNamara, Á., \& Collins, D. (2015). Profiling, exploiting, and countering psychological characteristics in talent identification and development. The Sport Psychologist, 29(1), 73-81. doi:10.1123/tsp.2014-0021

Nicholls, A. R., Holt, N. L., \& Polman, R. C. J. (2005). A phenomenological analysis of coping effectiveness in golf. Sport Psychologist, 19(2), 111-130.

Nicholls, A. R., \& Polman, R. C. J. (2007). Coping in sport: A systematic review. Journal of Sports Sciences, 25(1), 11-31. doi:10.1080/02640410600630654

Nicholls, A. R., Taylor, N. J., Carroll, S., \& Perry, J. L. (2016). The development of a new sport-specific classification of coping and a meta-analysis of the relationship between different coping strategies and moderators on sporting outcomes. Frontiers in Psychology, 7(1674), 1-14. doi:10.3389/fpsyg.2016.01674

Orlick, T., \& Partington, J. (1988). Mental links to excellence. The Sport Psychologist, 2, $105-130$.

Reardon, C. L., \& Factor, R. M. (2010). Sport psychiatry: A systematic review of diagnosis and medical treatment of mental illness in athletes. Sports Medicine, 40(11), 961-980. doi:10.2165/11536580-000000000-00000

Rice, S. M., Purcell, R., De Silva, S., Mawren, D., McGorry, P. D., \& Parker, A. G. (2016). The mental health of elite athletes: A narrative systematic review. Sports Medicine, 46(9), 1333-1353. doi:10.1007/s40279-016-0492-2

Richards, H. (2011). Chapter 20 - Coping and mental toughness. In D. Collins, A. Button, \& H. Richards (Eds.), Performance Psychology (pp. 281-300). Edinburgh: Churchill Livingstone. 
Rickwood, D., Deane, F. P., Wilson, C. J., \& Ciarrochi, J. (2005). Young people's helpseeking for mental health problems. Australian e-Journal for the Advancement of Mental Health, 4(3), 218-251. doi:10.5172/jamh.4.3.218

Rickwood, D., \& Thomas, K. (2012). Conceptual measurement framework for help-seeking for mental health problems. Psychology Research and Behavior Management, 5, 173183. doi:10.2147/PRBM.S38707

Roberts, C.-M., Faull, A. L., \& Tod, D. (2016). Blurred lines: Performance enhancement, common mental disorders and referral in the U.K. athletic population. Frontiers in Psychology, 7(1067), 1-13. doi:10.3389/fpsyg.2016.01067

Saunders, B., Sim, J., Kingstone, T., Baker, S., Waterfield, J., Bartlam, B., . . . Jinks, C. (2018). Saturation in qualitative research: exploring its conceptualization and operationalization. Quality \& quantity, 52(4), 1893-1907. doi:10.1007/s11135-0170574-8

Savage, J., Collins, D., \& Cruickshank, A. (2016). Exploring traumas in the development of talent: What are they, what do they do, and what do they require? Journal of Applied Sport Psychology, 29(1), 101-117. doi:10.1080/10413200.2016.1194910

Schaal, K., Tafflet, M., Nassif, H., Thibault, V., Pichard, C., Alcotte, M., . . Toussaint, J.-F. (2011). Psychological balance in high level athletes: Gender-based differences and sport-specific patterns. PLOS ONE, 6(5), 1-9. doi:10.1371/journal.pone.0019007

Schinke, R. J., Stambulova, N. B., Si, G., \& Moore, Z. (2017). International society of sport psychology position stand: Athletes' mental health, performance, and development. International Journal of Sport and Exercise Psychology, 16(6), 622-639. doi:10.1080/1612197X.2017.1295557 
Sebbens, J., Hassmén, P., Crisp, D., \& Wensley, K. (2016). Mental health in sport (MHS): Improving the early intervention knowledge and confidence of elite sport staff. Frontiers in Psychology, 7(911), 1-9. doi:10.3389/fpsyg.2016.00911

Smith, B., \& McGannon, K. R. (2018). Developing rigor in qualitative research: Problems and opportunities within sport and exercise psychology. International Review of Sport and Exercise Psychology, 11(1), 101-121. doi:10.1080/1750984X.2017.1317357

Smith, J. A. (2011). Evaluating the contribution of interpretative phenomenological analysis. Health Psychology Review, 5(1), 9-27. doi:10.1080/17437199.2010.510659

Smith, J. A., \& Osborn, M. (2007). Interpretative phenomenological analysis. In J. A. Smith (Ed.), Qualitative psychology: A practical guide to research methods (2nd Edition) (pp. 53-80). London: Sage.

Swann, C., Moran, A., \& Piggott, D. (2015). Defining elite athletes: Issues in the study of expert performance in sport psychology. Psychology of Sport and Exercise, 16, 3-14. doi:10.1016/j.psychsport.2014.07.004

Talebi, M., Matheson, K., \& Anisman, H. (2016). The stigma of seeking help for mental health issues: Mediating roles of support and coping and the moderating role of symptom profile. Journal of Applied Social Psychology, 46(8), 470-482. doi:10.1111/jasp.12376

Toering, T. T., Elferink-Gemser, M. T., Jordet, G., \& Visscher, C. (2009). Self-regulation and performance level of elite and non-elite youth soccer players. Journal of Sports Sciences, 27(14), 1509-1517. doi:10.1080/02640410903369919

WHO. (2018). Depression. Retrieved from http://www.who.int/en/news-room/factsheets/detail/depression 
854 Wolanin, A., Gross, M., \& Hong, E. (2015). Depression in athletes: Prevalence and risk

855 factors. Current Sports Medicine Reports, 14(1), 56-60.

856 doi:10.1249/jsr.0000000000000123

857 


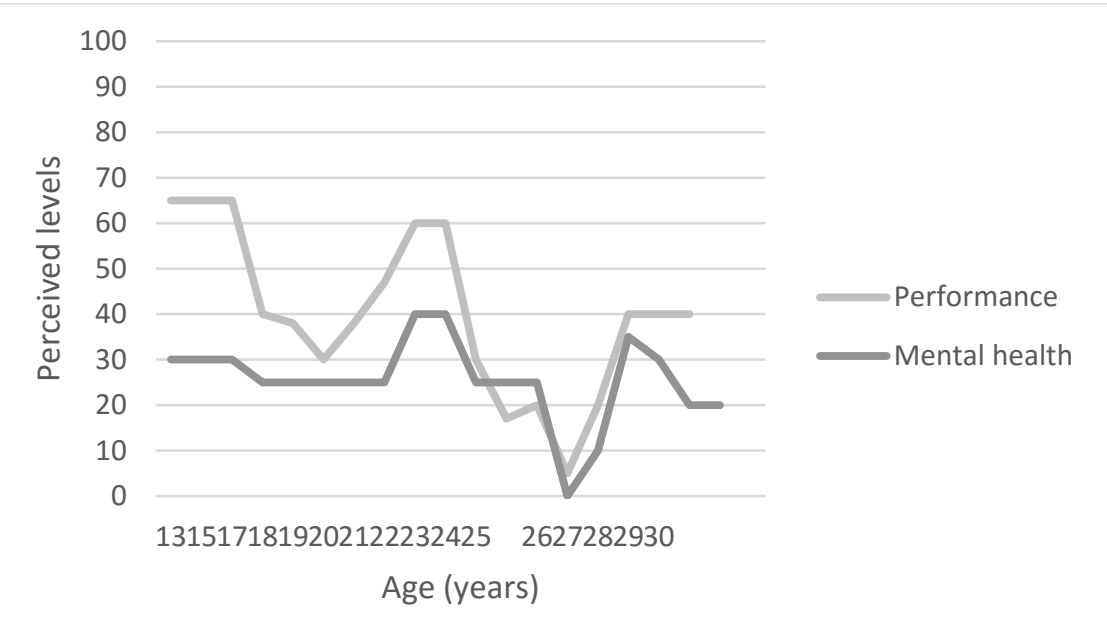

Figure 1. Participant 1's graphic timeline

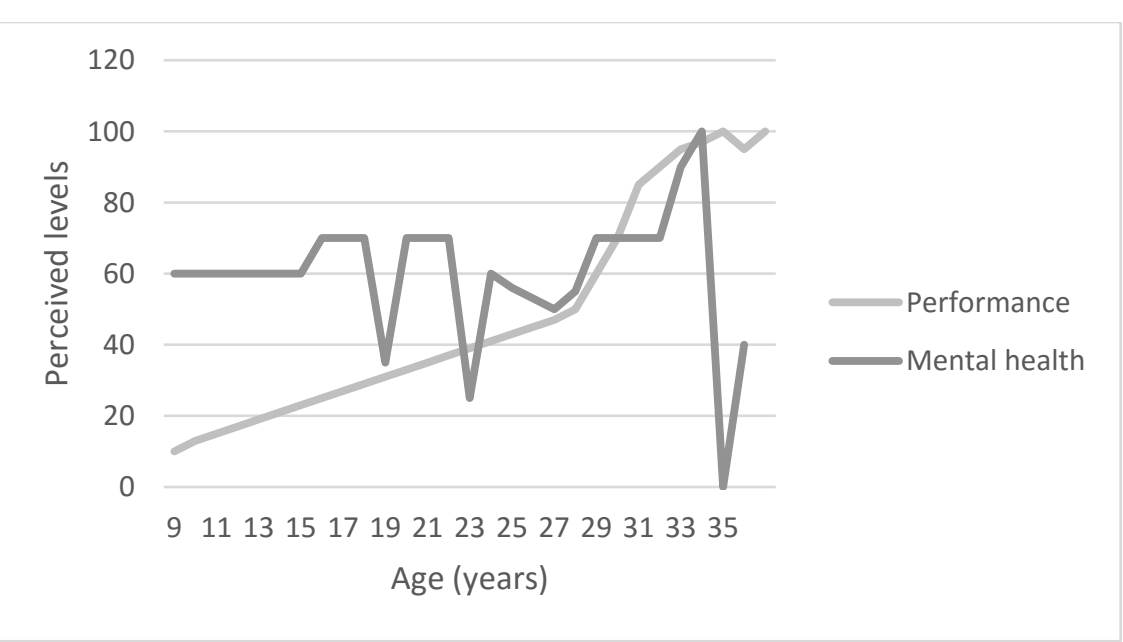

Figure 3. Participant 3's graphic timeline

Figures reproduced from Lebrun, MacNamara, Rodgers, and Collins (2018)

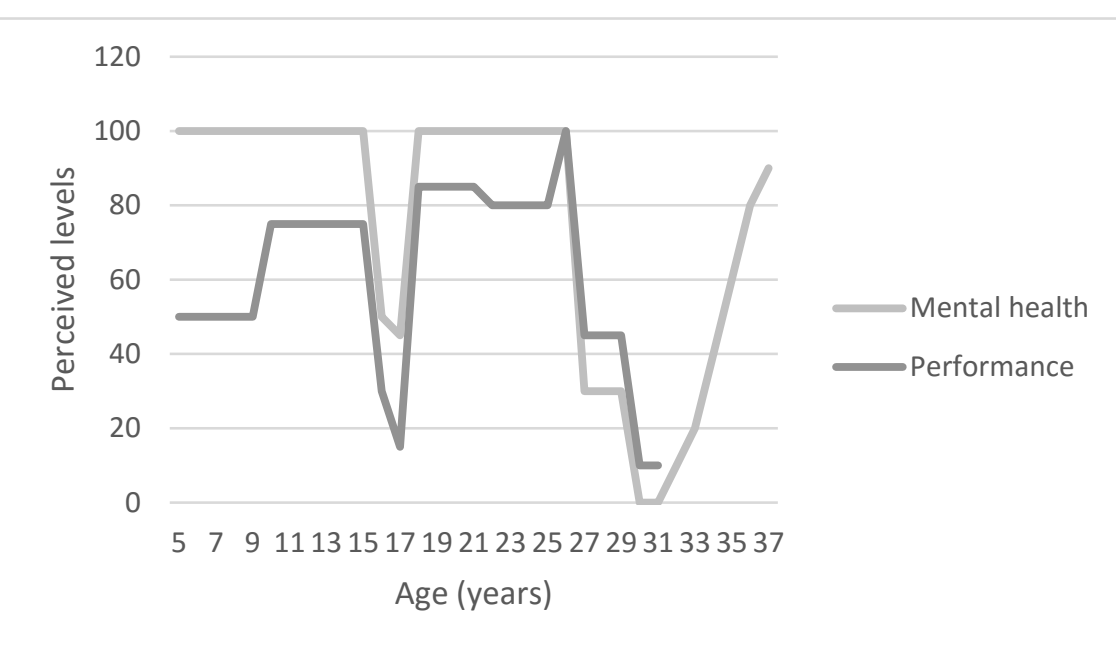

Figure 2. Participant 2's graphic timeline

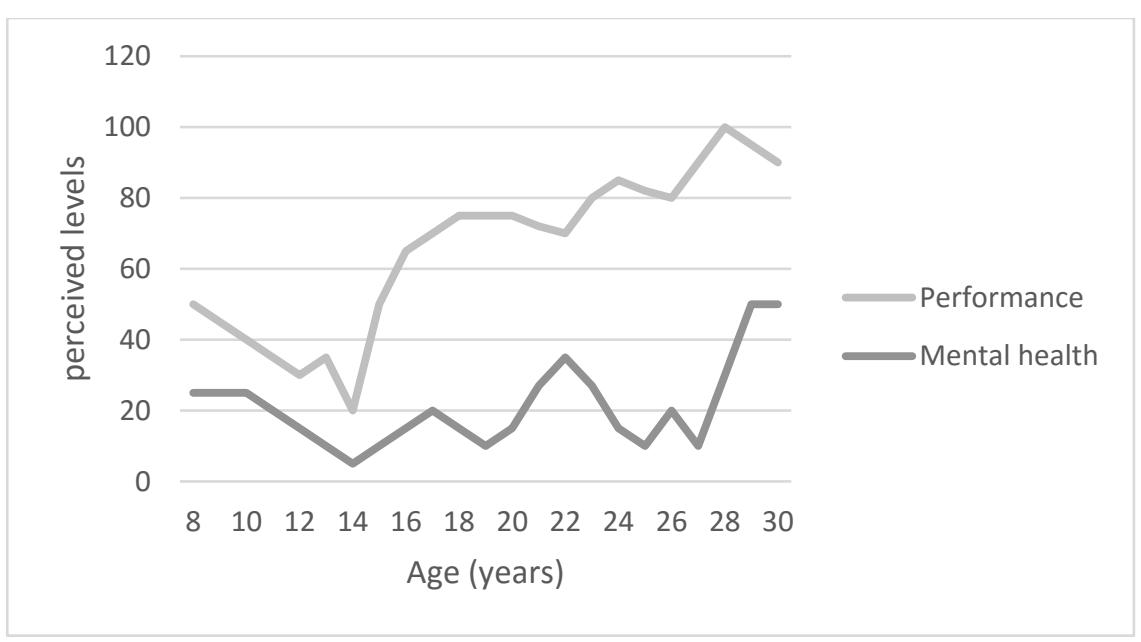

Figure 4. Participant 4's graphic timeline 